\title{
Proteomics Reveals the Changes that Contribute to Fusarium Head Blight Resistance in Wheat
}

\author{
Mingming Yang, ${ }^{1,2}$ Xianguo Wang, ${ }^{1}$ Jian Dong, ${ }_{1,2}$ Wanchun Zhao, ${ }^{1,2}$ Tariq Alam, ${ }^{3}$ Linda S. Thomashow, ${ }^{4}$ David M. \\ Weller, ${ }^{4}$ Xiang Gao, ${ }^{1,2, \dagger}$ Sachin Rustgi, ${ }^{3, \dagger}$ and Shanshan Wen ${ }^{1, \dagger}$ \\ ${ }^{1}$ College of Agronomy, Northwest A\&F University, Yangling 712100, People's Republic of China \\ ${ }^{2}$ Wheat Engineering Research Center of Shaanxi Province, Yangling 712100, People's Republic of China \\ ${ }^{3}$ Department of Plant and Environmental Sciences, Clemson University Pee Dee Research and Education Center, Florence, SC 29506, U.S.A. \\ ${ }^{4}$ Wheat Health, Genetics, and Quality Research Unit, U.S. Department of Agriculture-Agricultural Research Service, Pullman, WA 99164- \\ 6430, U.S.A. \\ Accepted for publication 22 July 2020.
}

\begin{abstract}
Fusarium head blight (FHB) is a devastating disease of wheat, causing yield losses and quality reduction as a result of mycotoxin production. In this study, iTRAQ (isobaric tags for relative and absolute quantification)labeling-based mass spectrometry was employed to characterize the proteome in wheat cultivars Xinong 538 and Zhoumai 18 with contrasting levels of FHB resistance as a means to elucidate the molecular mechanisms contributing to FHB resistance. A total of 13,669 proteins were identified in the two cultivars $48 \mathrm{~h}$ after Fusarium graminearum inoculation. Among these, 2,505 unique proteins exclusively accumulated in Xinong 538 (resistant) and 887 proteins in Zhoumai 18 (susceptible). Gene Ontology enrichment analysis showed that most differentially accumulated proteins (DAPs) from both cultivars were assigned to the following categories: metabolic process, single-organism process, cellular process, and re-

pathways were identified in Xinong 538 compared with Zhoumai 18. Specifically, DAPs from the FHB-resistant cultivar Xinong 538 populated categories of metabolic pathways related to plant-pathogen interaction. These DAPs might play a critical role in defense responses exhibited by Xinong 538. DAPs from both genotypes were assigned to all wheat chromosomes except chromosome 6B, with approximately $30 \%$ mapping to wheat chromosomes $2 \mathrm{~B}, 3 \mathrm{~B}, 5 \mathrm{~B}$, and $5 \mathrm{D}$. Twenty single nucleotide polymorphism markers, flanking DAPs on chromosomes $1 \mathrm{~B}, 3 \mathrm{~B}, 5 \mathrm{~B}$, and $6 \mathrm{~A}$, overlapped with the location of earlier mapped FHB-resistance quantitative trait loci. The data provide evidence for the involvement of several DAPs in the early stages of the FHB-resistance response in wheat; however, further functional characterization of candidate proteins is warranted.
\end{abstract} sponse to stimulus. Kyoto Encyclopedia of Genes and Genomes analysis showed that a greater number of proteins belonging to different metabolic
Keywords: disease control, genetics, pest management, resistance
Head blight caused by Fusarium graminearum is a significant disease of cereals that not only compromises yield but also reduces grain quality and safety of food/feed as a result of the accumulation of mycotoxins such as deoxynivalenol, nivalenol, and zearalenone (Bottalico and Perrone 2002; Eldakak et al. 2018). F. graminearum has a broad host range and causes disease in durum wheat (Triticum durum Desf.), maize (Zea mays L.), triticale (Triticosecale Wittm.), oat (Avena sativa L.), and rice (Oryza sativa L.) (Langevin et al. 2004; Miedaner et al. 2001).

Multiple defense and resistance mechanisms are known to exist in plants. Two main types of resistance to Fusarium head blight (FHB) are type I (resistance to initial infection) and type II (resistance to fungal spread within the host) (Schroeder and Christensen 1963).

†Corresponding authors: X. Gao; gx@nwsuaf.edu.cn, S. Rustgi; srustgi@clemson.edu, and S. Wen; sswen@nwsuaf.edu.cn

Funding: This work was supported by grants from the National Science and Technology Projects for Rural Areas During the 12th Five-Year Plan Period (2011AA100501), Fundamental Research Funds for the Central Universities (Z109021623), Chinese Postdoctoral Science Foundation (2016M602871), National Natural Science Foundation of China (31801443 and 31701425), China Scholarships Council (201806305044), and Project Supported by Natural Science Basic Research Plan in Shaanxi Province of China (Program 2019JQ-514). This work was also supported by a NIFA Hatch/Multi-State Grant (S009).

M. Yang and X. Wang contributed equally to this work.

*The $\boldsymbol{e}$-Xtra logo stands for "electronic extra" and indicates that three supplementary figures, six supplementary tables, and one supplementary appendix are published online.

The author(s) declare no conflict of interest.

(c) 2021 The American Phytopathological Society
Many quantitative trait loci (QTLs) were identified to contribute to FHB resistance in wheat (Liu et al. 2009; Wang et al. 2019). Among these, one of the best-described sources of resistance is the Sumai3 Fhbl locus, also known as $Q f h s . n j a u-3 B$. According to a 2019 study, resistance conferred by this locus is determined by a rare deletion at the 3 -exon of the histidine-rich calcium binding protein ( $\mathrm{Li}$ et al. 2019). However, a parallel study concluded that the deletion spanning the start codon of the gene determined resistance conferred by the locus (Hao et al. 2020; Su et al. 2019). As stated earlier, FHB resistance is a multigenic trait and the Fhbl locus explains only part of the variation that exists for the trait; therefore, the other genes contributing to FHB resistance still need to be investigated. In 2020, a resistance gene, $F h b 7$, that encodes a glutathione $S$-transferase from a wild wheat relative, Thinopyrum elongatum, was shown to provide a moderate level of resistance against both FHB and Fusarium crown rot (Wang et al. 2020). The two genes, Fhbl and Fhb7, could be stacked to increase resistance, but the initial findings indicated only a little improvement in FHB resistance with gene pyramiding (Stokstad 2020). This result further reinforces the need to dissect the genetics of FHB resistance and identify more genes that contribute to it.

Proteomics is a promising tool to investigate the molecular dialogue between a host and a pathogen. Proteomics investigations have been performed in Fusarium-infected barley (Shin et al. 2011; Yang et al. 2010a; Zhou et al. 2006), wheat (Eldakak et al. 2018; Fabre et al. 2019; Liu et al. 2019; Perlikowski et al. 2014; Wang et al. 2005; Zhou et al. 2006), and triticale (Eggert and Pawelzik 2011; Eggert et al. 2011). These results showed that during the initial infection of wheat and barley spikes by $F$. graminearum, many proteins related to carbon metabolism, photosynthesis, oxidative stress, and fungal cell wall degradation were expressed differentially. In addition, pathogenesis-related proteins such as chitinase, 
augmentin-like proteins, and proteins involved in the oxidative stress response showed preferential accumulation (Fabre et al. 2019; Kosová et al. 2017; Yang et al. 2010a). Infection of emmer wheat by $F$. graminearum was also studied at early and late grain developmental stages (Trümper et al. 2015), and 43 proteins that differentially accumulated were identified. In the early stages of grain development, an increase in the abundance of proteins related to stress response, such as 2-Cys peroxiredoxin, a chitinase, a xylanase inhibitor, and a spermidine synthase, was observed. Later, a decreased abundance of stress-related proteins, including chitinases, heat shock proteins, and $\alpha$-amylase inhibitor-like protein, was documented. During grain ripping stages including the medium milk and soft dough stages, an increased abundance of proteins related to carbon metabolism, photosynthesis, and starch/protein biosynthesis was reported (Trümper et al. 2015). Another study investigated the molecular interactions between wheat and Fusarium infection for $96 \mathrm{~h}$ (Fabre et al. 2019). That study aimed to compare the stress response in plant genotypes with different levels of stress adaptability and revealed constitutively enhanced accumulation of several stress-related proteins in the tolerant genotypes, with the ability to modulate metabolism to fit enhanced energy needs during infection and associated mounting stress levels (Eggert et al. 2011).

Despite these efforts to decipher the biology of the Fusariumwheat infection process (Yang et al. 2013), there are still many gaps in our understanding of the interaction. This study is an effort toward resolving these knowledge gaps. The specific objective of this study was to compare the proteomes of an FHB-susceptible wheat cultivar and an FHB-resistant wheat cultivar in the presence or absence of Fusarium infection. The results are expected to shed light on the molecular mechanism of resistance/tolerance to FHB in wheat cultivar Xinong 538 and the proteins contributing to it.

\section{MATERIALS AND METHODS}

Plant materials and growth conditions. Two winter wheat cultivars, Xinong 538 and Zhoumai 18, were used in this study. Pregerminated seeds of these cultivars were sown in plastic pots (30 cm diameter $\times 40 \mathrm{~cm}$ deep) filled with Miracle-Gro potting mix (Scotts Miracle-Gro, Marysville, $\mathrm{OH}$ ) and transferred to a controlled climate chamber (BIC-300; Boxun, Shanghai, China) set to a temperature regimen of $25^{\circ} \mathrm{C}$ day and $20^{\circ} \mathrm{C}$ night with a $14-\mathrm{h}$ photoperiod. After growing for a week, seedlings were transferred to an incubator adjusted to $4{ }^{\circ} \mathrm{C}$ and a 14-h photoperiod for 28 days. Following cold treatment, the seedlings were moved to the greenhouse maintained at $25^{\circ} \mathrm{C}$ day and $20^{\circ} \mathrm{C}$ nighttime temperatures. Type II FHB resistance evaluation of cultivars was performed by single-floret inoculation at anthesis, in which florets of the third or fourth spikelets from the tip of the spike were challenged with a $10-\mu l$ water suspension of $F$. graminearum conidia (about 50,000 conidia/ $\mu l$ ). Inoculated spikes were covered with a plastic bag for $48 \mathrm{~h}$ to maintain humidity. Spikes inoculated with water were used as a negative control. The experiment consisted of four treatments: A, Xinong 538 mock; B, Xinong 538 inoculated with $F$. graminearum; C, Zhoumai 18 mock; and $\mathrm{D}$, Zhoumai 18 inoculated with $F$. graminearum. In each case, $48 \mathrm{~h}$ after inoculation, the inner glumes were collected in liquid nitrogen and kept at $-80^{\circ} \mathrm{C}$ until used.

Protein extraction and isobaric tags for relative and absolute quantification labeling. Frozen glumes of three biological replicates each of two wheat cultivars were sampled after the FHB and mock treatments and used for protein extraction as described by Yang et al. (2017). The protein concentration was determined via the standard bicinchoninic acid assay using bovine serum albumin as the standard (Beyotime, Shanghai, China). Approximately $100 \mu \mathrm{g}$ of protein from each sample was trypsinized and labeled using the isobaric tags for relative and absolute quantification (iTRAQ) 4-plex kit (AB SCIEX) following the manufacturer's instructions.

High-pH reversed-phase chromatography. iTRAQ-labeled samples were diluted in $100 \mu \mathrm{l}$ of high-performance liquid chromatography (HPLC)-grade water with $20 \mathrm{mM}$ of ammonium formate $\left(\mathrm{HCOONH}_{4}\right)$ and $2 \mathrm{M}$ of $\mathrm{NaOH}(\mathrm{pH} 10)$ before HPLC on a Gemini $3 \mu \mathrm{m}$ NX-C18 $110 \AA$ A $(150 \times 2.00$ mm) column (Phenomenex, Torrance, CA). Peptides were separated by a linear gradient of 5 to $40 \%$ of mobile phase $\mathrm{B}\left(20 \mathrm{mM}\right.$ of $\mathrm{HCOONH}_{4}, 2 \mathrm{M}$ of $\mathrm{NaOH}$, and

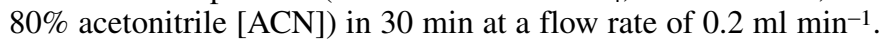
Absorbance was monitored at a detection wavelength of 214/ $280 \mathrm{~nm}$ via an ultraviolet detector. Fractions were collected every $1 \mathrm{~min}$ and dried using a vacuum centrifuge.

Electrospray ionization tandem mass spectrometric analysis. After acidification with $50 \%$ trifluoroacetic acid $\left(\mathrm{CF}_{3} \mathrm{COOH}\right)$, peptides were separated on a linear gradient of mobile phase $\mathrm{B}(80 \%$ ACN plus $0.1 \%$ formic acid [FA]) in mobile phase $\mathrm{A}(5 \% \mathrm{ACN}$ plus $0.1 \% \mathrm{FA}$ ) from 5 to $90 \%$ in $50 \mathrm{~min}$ at a flow rate of $300 \mathrm{ml} \mathrm{min} \mathrm{m}^{-1}$. The Q Exactive system (Thermo Scientific) in informationdependent mode was used to perform tandem mass spectrometry (MS/MS) analysis. Mass spectra were acquired across the mass range of 350 to $1,800 \mathrm{~m} / \mathrm{z}$ in high-resolution mode $(>70,000)$ using $40-\mathrm{ms}$ accumulation time per spectrum. A maximum of 20 precursors per cycle was chosen for fragmentation from each mass spectrum, with 60-ms minimum accumulation time for each precursor and dynamic exclusion for $20 \mathrm{~s}$. Tandem mass spectra were recorded in high sensitivity mode (resolution $>17,500$ ) with rolling collision energy and iTRAQ reagent collision energy adjustments turned on.

Protein identification and quantification. MS/MS spectra were searched against the Uniprot wheat protein database (https:// www.uniprot.org/proteomes/UP000019116) using Proteome Discoverer software version 2.1 (Thermo Fisher Scientific). For protein identification, we used the following parameters: trypsin digestion; dynamic modification; false discovery rate determination for all peptides, and protein identifications $<1 \%$; precursor ion mass tolerance, $\pm 15 \mathrm{ppm}$; fragment ion mass tolerance, \pm 20 millimass units; and maximum missed cleavages. The MS data acquisition peak files were deposited in the ProteomeXchange repository (PX; http://www.proteomexchange.org) under Integrated Proteome Resource (iProX; https://www.iprox.org). A protein containing at least two unique peptides was considered for quantitation. Proteins with a fold change $>1.2$ or $<0.83(P<0.05)$ in the three biological replicates were considered as the differentially accumulated protein (DAP) species.

Bioinformatics analysis. Hierarchical clustering was conducted using the plots package of R (http://cran.r-project.org/web/ packages/gplots/). Gene Ontology (GO) annotation for functional analysis was performed, and proteins were classified based on molecular function, biological process, and cellular components. For pathway analysis, annotations using the Kyoto Encyclopedia of Genes and Genomes (KEGG) (https://www.kegg.jp/) were performed. Venn diagrams were generated for the up- and downregulated protein species using Venny software (version 2.1; http://bioinfogp.cnb.csic. es/tools/venny/index.html). Principal component analysis and orthogonal partial least-squares discriminant analysis were performed using SIMCA software (version 14.1; Umetrics, Umea, Sweden). For the above analysis, the predictive components were considered at variable importance in the projection $>1$ and correlation coefficient $\mid$ pcorr $\mid>0.6$.

Quantitative PCR. Quantitative reverse transcription PCR (qRT-PCR) was carried out to investigate the correspondence between gene expression level and protein accumulation. Genes coding for the synthesis of chitinase IV, thaumatin-like 1, PR1.1, and PR1.2, were selected for this analysis. Total RNA was isolated using TRIzol reagent (Invitrogen) following the manufacturer's instructions and converted to cDNA using the PrimeScript RT Reagent Kit with the gDNA Eraser (Takara). Primers were designed using Primer-BLAST software (https://www.ncbi.nlm.nih.gov/ tools/primer-blast) (see Supplementary Table S6 for primer details). The 18S rRNA was used as a reference to normalize gene expression data. RT-PCR reactions were performed in $20-\mu 1$ volumes containing $9 \mu \mathrm{l}$ of the $2.5 \times$ RealMasterMix/20× SYBR solution, 
$2 \mu \mathrm{l}$ of cDNA, $0.4 \mu \mathrm{l}$ of each primer (adjusted to $5 \mu \mathrm{M}$ ), and $7.2 \mu \mathrm{l}$ of $\mathrm{ddH}_{2} \mathrm{O}$. PCR conditions were as follows: $95^{\circ} \mathrm{C}$ for $3 \mathrm{~min}$, and 45 cycles of $15 \mathrm{~s}$ at $95^{\circ} \mathrm{C}, 15 \mathrm{~s}$ at $57^{\circ} \mathrm{C}$, and $20 \mathrm{~s}$ at $72^{\circ} \mathrm{C}$. Three biological and two technical replicates were used per genotype per treatment. All data were analyzed using CFX Manager software (Bio-Rad).

Genomic localization of DAPs. Genomic locations of DAPs on wheat subgenomes, homeologous chromosome groups, and specific chromosomes were determined using BLAST searches against IWGSC RefSeq (version 1.0) at the URGI database (https:// wheat-urgi.versailles.inra.fr/Seq-Repository/BLAST). The variation in chromosome sizes and gene number was accounted for by calculating the expected number of DAPs mapping to each chromosome (Yang et al. 2017, 2020) as follows:

\section{$\sum$ DAPs $(n)$ \\ $\overline{\sum \text { Genes }(n) \text { or Genome size }} \times$ \\ $\sum$ Genes mapping to a chromosome $(n)$ or Chromosome size}

Expected and observed numbers of DAPs per chromosome were plotted as bar graphs to facilitate comparisons. Wheat chromosome zippers were used to determine the subchromosomal distribution of DAPs and the identification of molecular markers flanking each DAP. The distribution of DAPs on each chromosome was determined and plotted as line diagrams following Yang et al. (2020). In each plot, the expected number of DAPs was calculated as follows considering the even distribution of genes on the chromosome, and it was shown as an arbitrary threshold line on the plots.

\section{¿DAPs mapping to a chromosome $(n)$ Chromosome size (cM) \\ $\times$ Size of an arbitrary bin $(\mathrm{cM})$}

Association of molecular markers flanking each DAP with known FHB QTLs was determined via the literature survey.

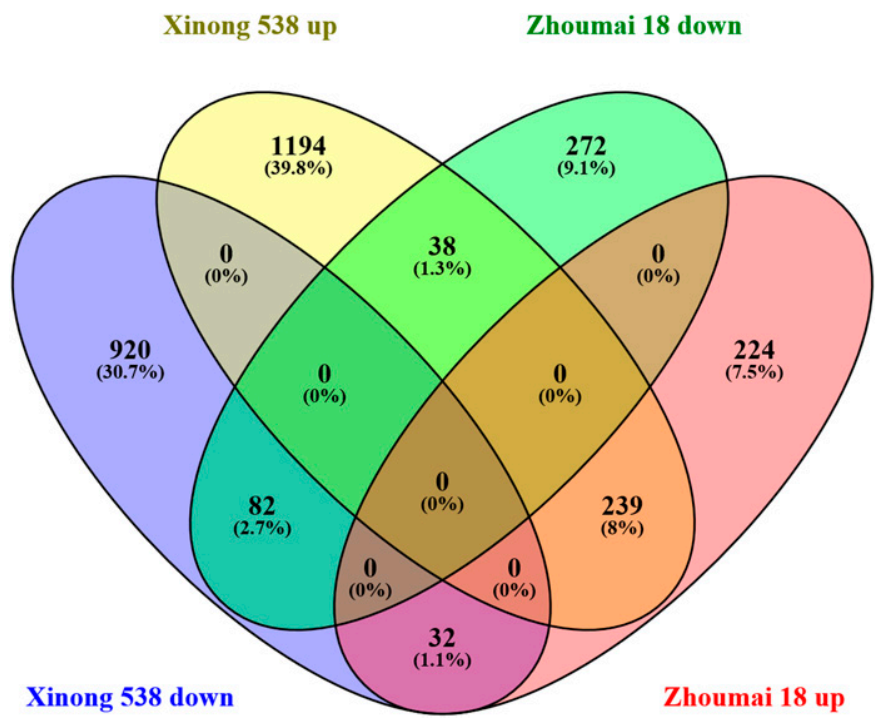

Fig. 1. Venn diagrams of differentially accumulated proteins from Xinong 538 and Zhoumai 18 in response to Fusarium head blight.

\section{RESULTS}

Protein identification and quantification. In this study, iTRAQ-based quantitative proteome profiling before and after $F$. graminearum infection was performed to identify proteins involved in the disease defense response of wheat cultivar Xinong 538. Global profiling of the quantitative proteome was obtained before inoculation and $48 \mathrm{~h}$ after inoculation with $F$. graminearum in wheat cultivars, Xinong 538 (FHB resistant) and Zhoumai 18 (FHB susceptible). Overall, $>85,321$ unique peptides, corresponding to 13,669 proteins, were identified (Table 1). Among the statistically significant proteins detected by analysis of variance $(P<0.05)$, the abundance of 3,001 unique proteins changed by $>1$.2-fold, of which 2,114 proteins were identified from Xinong 538, 496 proteins from Zhoumai 18, and 391 proteins from both cultivars (Fig. 1; Supplementary Table S1). Among the 2,505 (2,114 plus 391) proteins identified in Xinong 538, 1,034 showed reduced accumulation and 1,471 proteins exhibited enhanced accumulation; in Zhoumai 18, of 887 proteins (496 plus 391), 392 showed downregulation and 495 showed upregulation.

GO annotation of the DAPs and their associations with signaling pathways. A GO category enrichment analysis was conducted for proteins with $\geq 1$. 2 -fold change in their abundance to identify the functional categories enriched during FHB infection and categorized according to the GO Slim classification for plants. GO annotation and categorization of DAPs in major categories, such as biological process, cellular component, and molecular function, is shown in Figures 2 and 3.

In the biological process category, DAPs from Xinong 538 and Zhoumai 18 fell mainly into three subcategories (metabolic process, single-organism process, and cellular process), but in each subcategory, more DAPs originated from Xinong 538 than from Zhoumai 18. More precisely, in these subcategories, DAPs from both cultivars were enriched in the following sub-subcategories: macromolecule metabolic process, cellular macromolecule metabolic process, cellular nitrogen compound metabolic process, oxidation-reduction process, response to oxidative stress, and defense response. Under the molecular function category, most DAPs from both cultivars belonged to the binding subcategory and showed enrichment in the following sub-subcategories: anion binding, cation binding, nucleotide binding, nucleoside phosphate binding, ribonucleotide binding, and nucleic acid binding. The DAPs in the catalytic activity subcategory showed enrichment in the following sub-subcategories: peptidase activity, hydrolase activity, transferase activity, and oxidoreductase activity. Similarly, in the cellular component category, most enrichment of proteins from both cultivars was observed in the subcategories cell, membrane, and organelle and in the sub-subcategories cytoplasm, cytoplasm part, intracellular membrane-bounded organelle, integral component of membrane, intracellular ribonucleoprotein complex, plastid part, thylakoid, and chromosome (Figs. 2 and 3; Supplementary Tables S2 and S3).

Pathway analysis via KEGG. Enrichment of DAPs from both cultivars Xinong 538 and Zhoumai 18 in different pathways was studied using KEGG. In this analysis, DAPs mainly exhibited enrichment in categories such as metabolic pathways, biosynthesis of secondary metabolites, phenylpropanoid biosynthesis, biosynthesis of antibiotics, microbial metabolism in diverse environments, ribosome, carbon metabolism, and biosynthesis of amino acids. About three times more proteins from Xinong 538 compared with Zhoumai 18 showed enrichment in the pathway categories mentioned above. For example, in Xinong 538, 26 DAPs showed enrichment in the plant-pathogen pathway category, while only five proteins from Zhoumai 18 fell under this pathway. DAP enrichment

TABLE 1. Number of spectra, peptides, and protein species identified by iTRAQ proteomic analysis ${ }^{\mathrm{a}}$

\begin{tabular}{|c|c|c|c|c|}
\hline Total spectra & Spectra identified & Peptides & Protein species & Differentially accumulated protein species \\
\hline 850,324 & 337,212 & 85,321 & 13,669 & 3,392 \\
\hline
\end{tabular}

a iTRAQ = isobaric tags for relative and absolute quantification. 
in two pathway categories, oxidative phosphorylation and protein processing in the endoplasmic reticulum, was observed exclusively in Xinong 538, compared with DAP enrichment in two categories, photosynthesis and carbon fixation in photosynthetic organisms, in Zhoumai 18 (Figs. 4 and 5). Altogether, DAPs from Xiong 538 fell in 78 pathways and DAPs from Zhoumai 18 fell in five different pathways (Supplementary Tables S4 and S5).
Correspondence between mRNA and protein abundance. Correspondence between protein abundance and mRNA accumulation was studied for the four selected genes using qRT-PCR analysis. The qRT-PCR and protein abundance data suggested that transcript levels correspond with protein abundance (Table 2). mRNA abundances of the Chitinase IV, Thaumatin-like 1, PR1.1, and $P R 1.2$ genes were significantly higher in Xinong 538 than Zhoumai

The number of Proteins

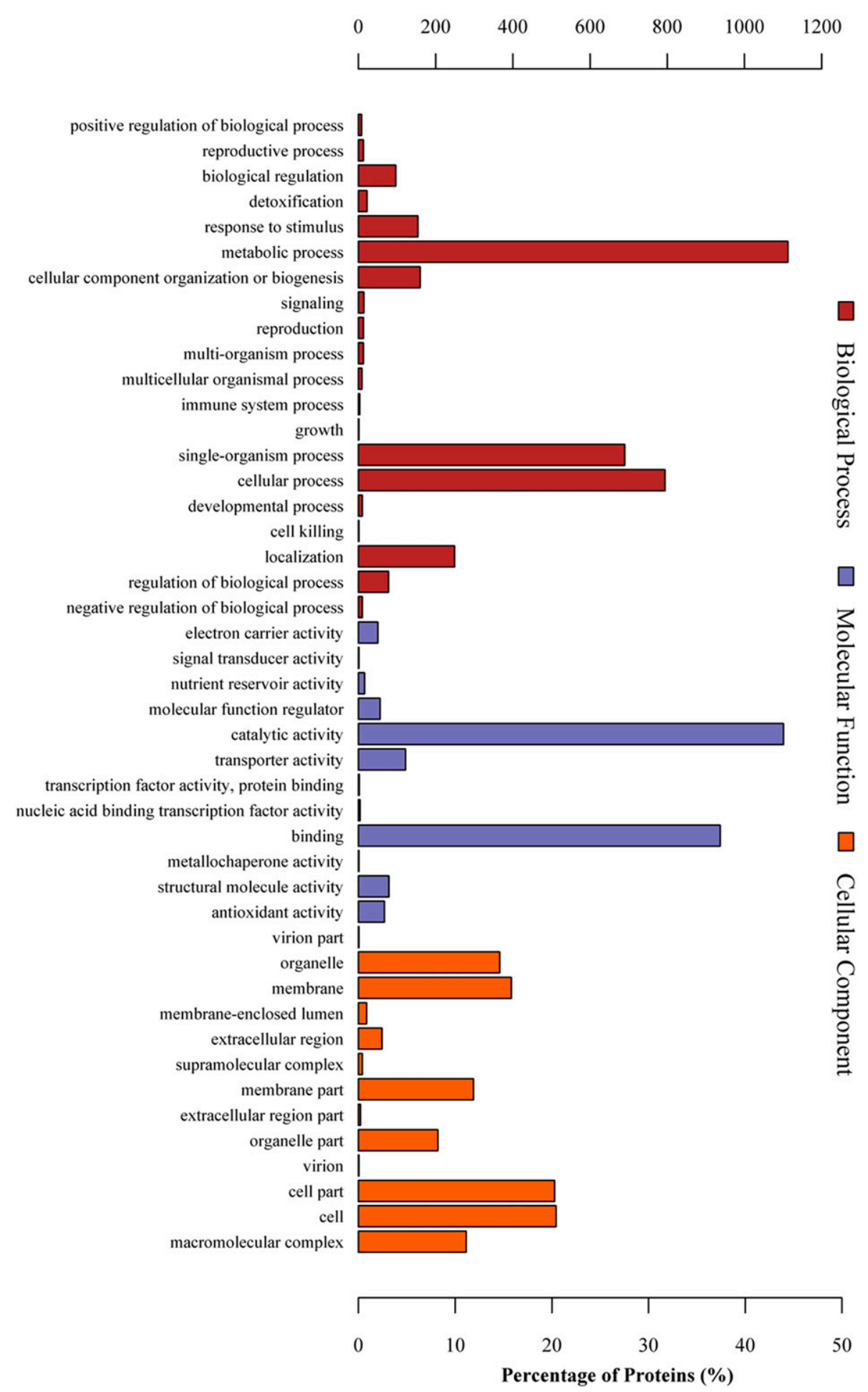

Fig. 2. Functional classification of differentially accumulated proteins according to Gene Ontology analysis in Xinong 538. Functional assignments are shown for the following categories: biological process, cellular components, and molecular function. 
18 at 2 days after inoculation (dai) (Fig. 6). These results corresponded well with the proteomics data for these genes.

Regulatory network contributing to FHB resistance. Diverse defense signaling pathways operate upon $F$. graminearum infection. We proposed a model to illustrate the early molecular events that lead to FHB resistance (Fig. 7). Three major reactions occurring during the first $48 \mathrm{~h}$ of Fusarium infection include $\mathrm{Ca}^{2+}$ and hormone signaling and the induction of the phenylalanine pathway. $\mathrm{Ca}^{2+}$ signaling might trigger stomatal closure; abscisic acid (ABA), salicylic acid (SA), and jasmonic acid (JA) signaling induces disease resistance genes; and the phenylalanine pathway promotes lignin biosynthesis leading to thickening of cell walls. Collectively, these reactions provide resistance to Fusarium infection.

Genomic localization of DAPs. Genomic locations of 371 of 391 DAPs (94.88\%; detected in both wheat cultivars) on specific

The number of Proteins

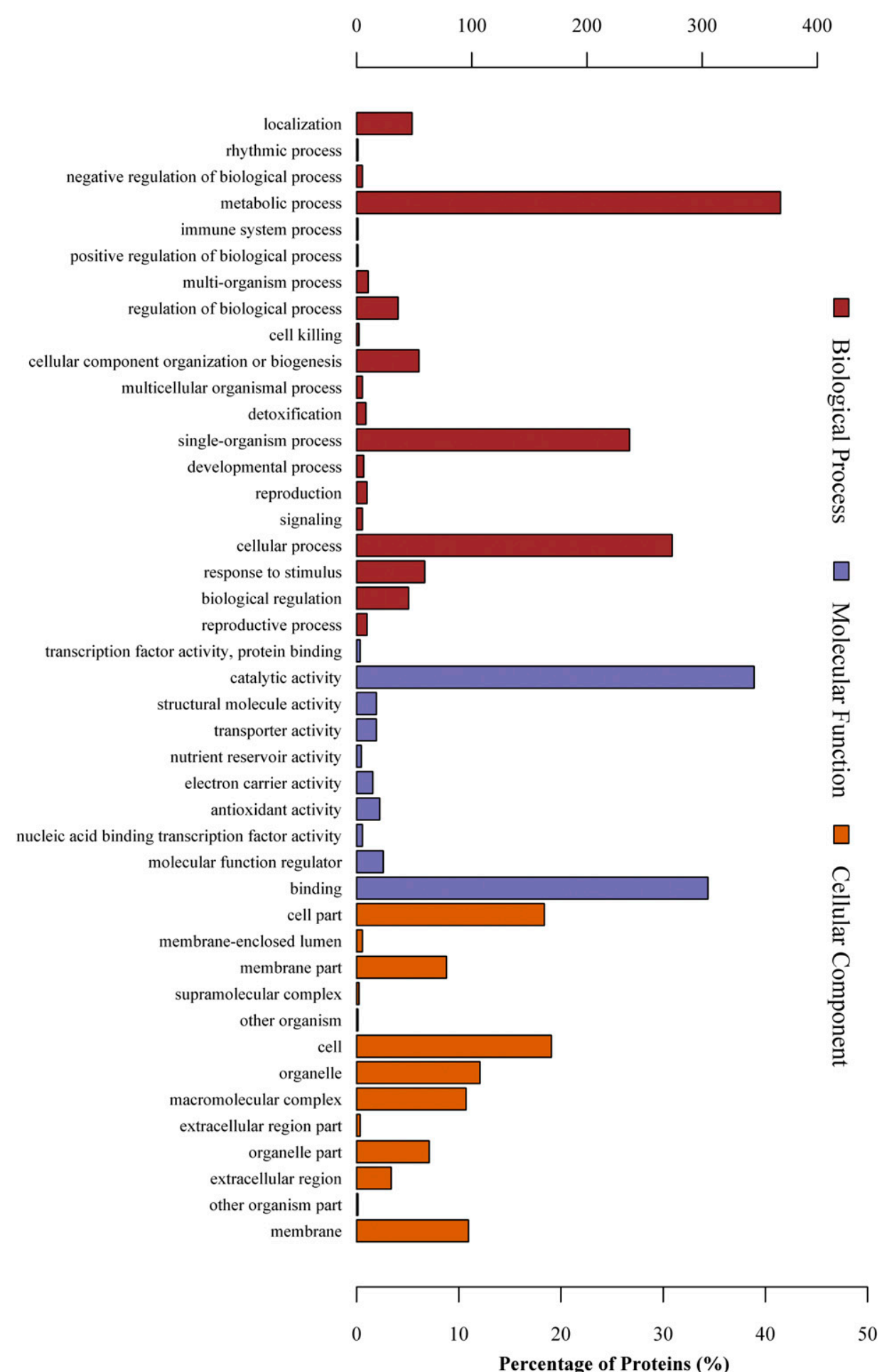

Fig. 3. Functional classification of differentially accumulated proteins according to Gene Ontology analysis in Zhoumai 18. Functional assignments are shown for the following categories: biological process, cellular components, and molecular function. 
wheat subgenomes, homeologous chromosome groups, specific chromosomes, and subchromosomal locations were determined (Figs. 8 and 9). The 20 remaining DAPs had no significant match in the mapped wheat sequences (IWGSC RefSeq version 1.0) available in the public database used for similarity search. Chromosome mapping revealed that more DAPs $(136 ; 36.66 \%)$ map to the D-subgenome of common wheat than B-subgenomes $(132 ; 35.56 \%)$ and A-subgenomes $(103 ; 27.76 \%)$ (Fig. $8 \mathrm{~A})$. At the chromosome level, after accounting for the variation in chromosome size and gene number per chromosome, more than the expected number of DAPs mapped to chromosomes 1A, 4A, 6A, 1B, 2B, 3B, 5B, 4D, 5D, 6D, and 7D (Fig. 8C to E). The highest number of DAPs mapped to chromosome $2 \mathrm{~B}(n=45)$, followed by 32 DAPs on chromosome $3 \mathrm{~B}$ and 29 DAPs on chromosomes $5 \mathrm{~B}$ and $5 \mathrm{D}$ (Supplementary Appendix S1).

DAPs were also assigned to wheat chromosome zippers, which facilitated identification of their respective locations on the genetic

\section{Percentage of Sequences (\%)}
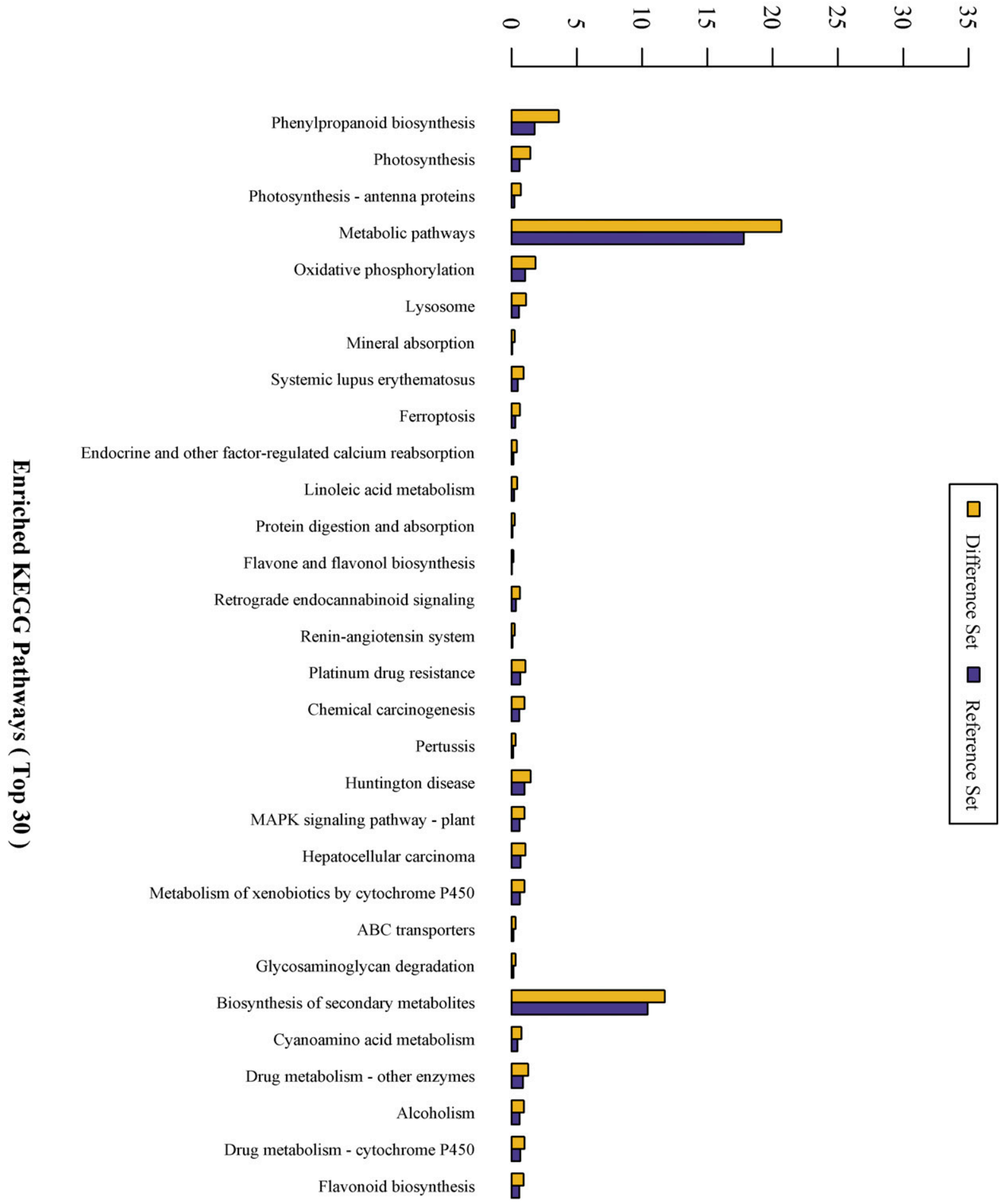

Fig. 4. Kyoto Encyclopedia of Genes and Genomes pathways analysis of differentially accumulated proteins in Xinong 538. MAPK = mitogen-activated protein kinase, and $\mathrm{ABC}=$ ATP-binding cassette. 
map and allowed identification of the flanking single nucleotide polymorphism (SNP) markers. DAPs showed a biased distribution on chromosomes; precisely, more DAPs mapped to the centromeric/ pericentromeric regions of chromosomes (Fig. 9; Supplementary Figs. S1, S2, and S3). Markers flanking the DAP map location on the composite chromosome maps were used in the literature survey to identify whether any of these markers were previously shown to be associated with FHB resistance. Twenty markers mapping to chromosomes $1 \mathrm{~B}, 3 \mathrm{~B}, 5 \mathrm{~B}$, and $6 \mathrm{~A}$ were previously identified to be associated with FHB resistance (Laskar et al. 2017). These markers mapped to four sites on chromosome 3B, three sites on chromosome $1 \mathrm{~B}$, two sites on chromosome $5 \mathrm{~B}$, and one site on chromosome $6 \mathrm{~A}$ (Fig. 9).

\section{DISCUSSION}

Proteomics can provide detailed information about the molecular events taking place during the host-pathogen interaction. An earlier

\section{Percentage of Sequences $(\%)$}

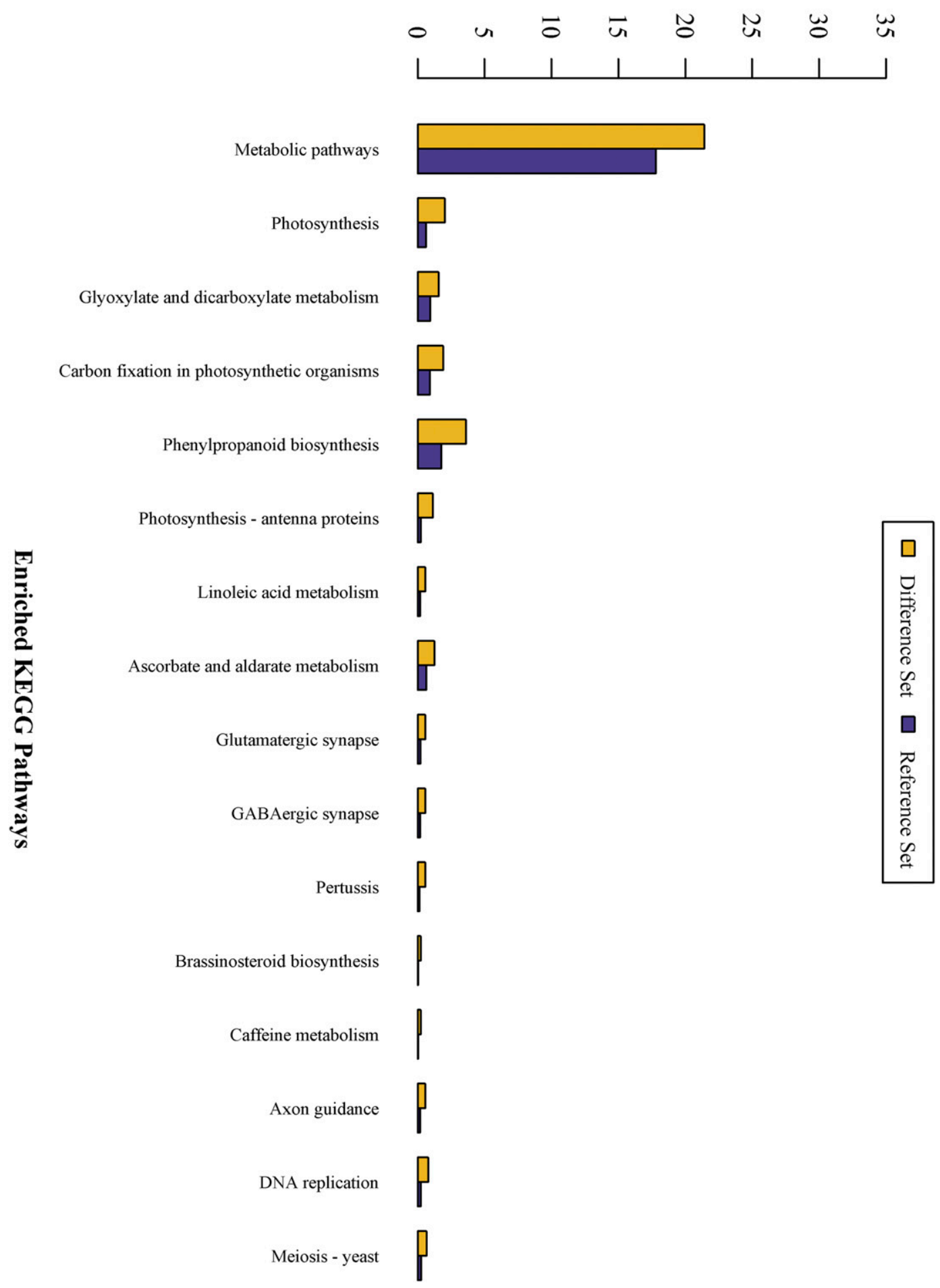

Fig. 5. Kyoto Encyclopedia of Genes and Genomes pathways analysis of differentially accumulated proteins in Zhoumai 18. 
study showed that 1,132 unique proteins accumulate in F. graminearuminfected wheat spikes. These proteins belonged to 19 different functional categories, with the greatest number falling into the category of binding proteins and metabolism (Fabre et al. 2019). In this study, >3,000 DAPs from a resistant cultivar and a susceptible cultivar were identified by using the iTRAQ technique, which enabled us to explore the molecular mechanisms contributing to FHB resistance. Many of these DAPs were involved in protein binding and metabolism, and further analysis showed that they were enriched in the categories of metabolic pathways, cell wall organization, and plant-pathogen interaction. This analysis suggests that these changes in protein abundance could potentially serve as biomarkers of FHB resistance in wheat (Wang et al. 2019).

Xinong 538 is a winter wheat cultivar released in 2011 that showed strong FHB resistance in the field and became the cultivar of choice in the Huanghuai area of China. Based on the gene array data, Xinong 538 carries the Fhb1 locus (unpublished data), which, to some extent, explains the strong FHB resistance shown by this cultivar in field evaluations. To investigate the molecular mechanisms contributing to FHB resistance of Xinong 538, we compared its proteome with that of the FHB-susceptible winter wheat cultivar Zhoumai 18, which is a hybrid between Neixiang 185 and Zhoumai

TABLE 2. mRNA and protein abundance changes of four selected genes ${ }^{\mathrm{a}}$

\begin{tabular}{|c|c|c|c|c|}
\hline \multirow[b]{2}{*}{ Gene } & \multicolumn{2}{|c|}{$\begin{array}{c}\text { mRNA (Xinong } \\
\text { 538/Zhoumai 18) }\end{array}$} & \multicolumn{2}{|c|}{$\begin{array}{c}\text { Protein (Xinong } \\
\text { 538/Zhoumai 18) }\end{array}$} \\
\hline & 0 dai & 2 dai & 0 dai & 2 dai \\
\hline Chitinase IV & 0.85 & 1.67 & 0.92 & 1.49 \\
\hline Thaumatin-like 1 & 1.12 & 3.25 & 0.74 & 1.33 \\
\hline PR1.1 & 1.25 & 2.32 & 0.46 & 2.37 \\
\hline PR1.2 & 0.93 & 1.77 & 0.7 & 1.4 \\
\hline
\end{tabular}

a dai = days after inoculation, and PR = pathogenesis related.

\section{Chitinase IV}

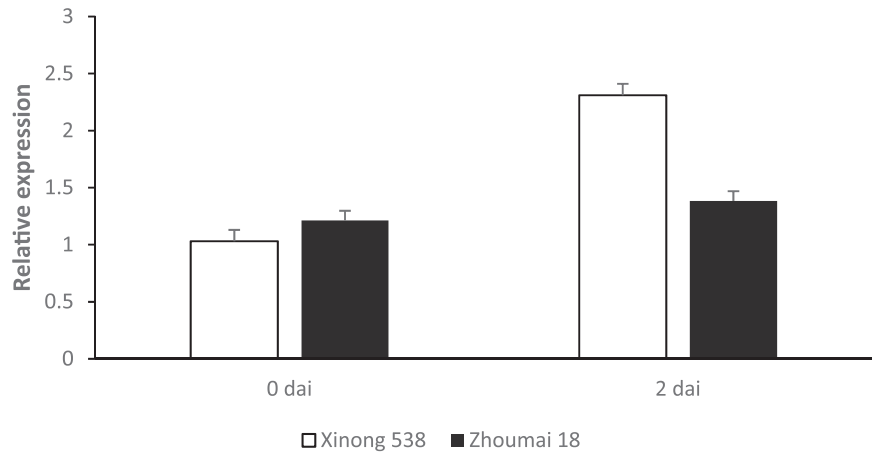

PR 1.2 gene

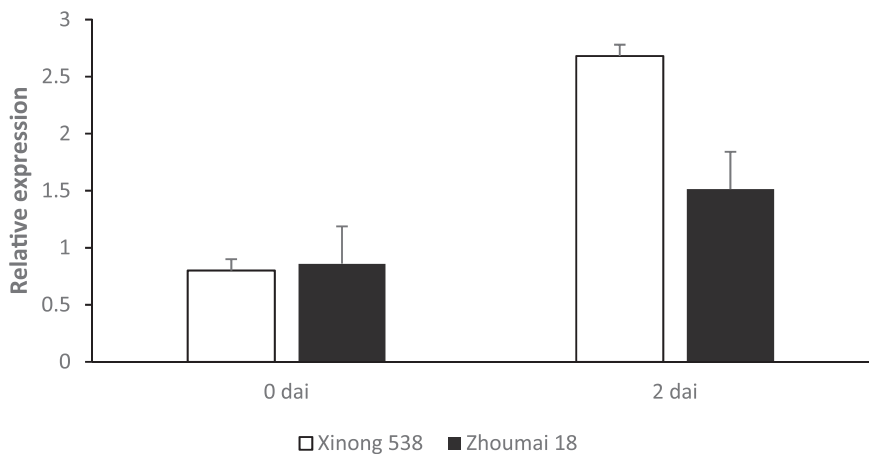

9 (Wang et al. 2012). At $48 \mathrm{~h}$ after inoculation with $F$. graminearum, more DAPs were found in Xinong $538(n=2,505)$ than in Zhoumai $18(n=887)$. Based on the KEGG analysis, these proteins primarily fell under the following categories: carbon metabolism, photosynthesis, plant hormone pathway, phenylpropanoid biosynthesis, and defenserelated responses. These results corroborate earlier findings in which defense-related proteins were found to express highly during early infection by $F$. graminearum (Eldakak et al. 2018; Fabre et al. 2019). Four defense-related genes (Chitinase IV, Thaumatin-like 1, PR1.1, and $P R 1.2$ ) were upregulated during $F$. graminearum infection in both cultivars, while a significantly higher expression level was observed in Xinong 538 compared with Zhoumai 18 (Fig. 6; Table 2). Geddes et al. (2008) reported that thaumatin-like proteins and the corresponding transcript overaccumulate in wheat heads in response to $F$. graminearum infection. In another study, Bernardo et al. (2007) reported a positive correlation between Thaumatin-like 1 expression and genotype-specific FHB resistance. In yet another study, expression of the rice thaumatin-like gene in wheat increased its resistance to F. graminearum (Chen et al. 1999). In this study, we found sevenfold upregulation of the thaumatin-like protein in Xinong 538 and 2.5-fold upregulation in Zhoumai 18. In comparison, at the transcript level, only a 1.33-fold increase in Thaumatin-like 1 expression was observed in Xinong 538 compared with Zhoumai 18. PR proteins have been identified as potential biomarkers of resistance during plant-pathogen interactions. Among them, PR1 family antimicrobial proteins are implied to be vital in host defense during pathogen infection (Gamir et al. 2017). In this study, six PR proteins (PR1, PR1.1, PR1.2, PR1.3, PR1.5, and PR1.19) were found to overaccumulate during $F$. graminearum infection. Both PR1 protein and the corresponding transcript were upregulated (twofold) in Xinong 538 compared with Zhoumai 18, suggesting that the PR1 family might contribute to FHB resistance. Similarly, an earlier study reported that overexpression of the transgenic defense response genes $\alpha$-1-purothionin, Thaumatin-like protein 1, and $\beta$-1,3-glucanase in wheat reduces FHB disease severity under

Thaumatin like 1 gene

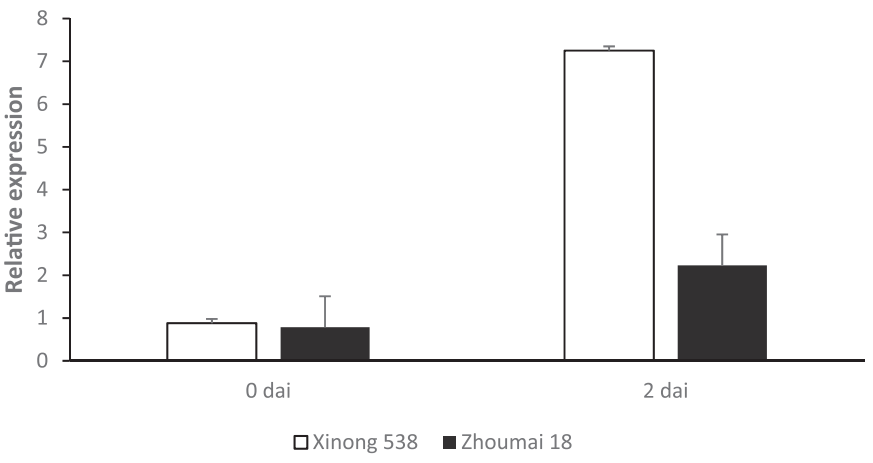

PR 1.1 gene

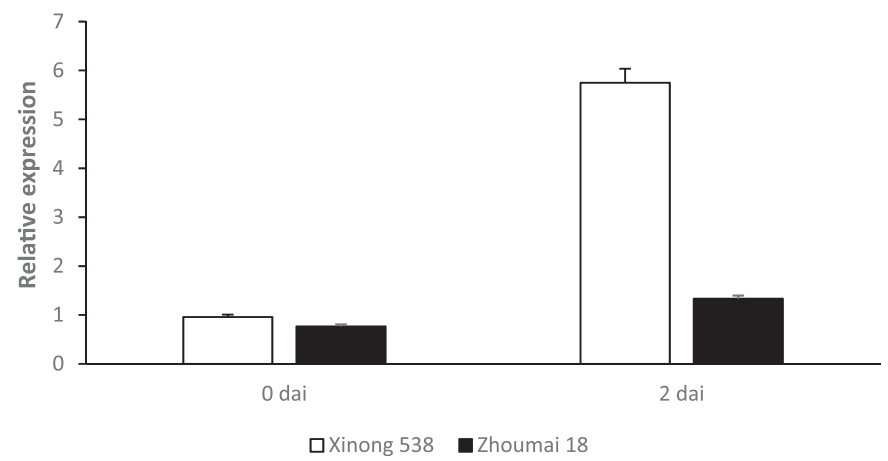

Fig. 6. Relative mRNA expression levels of the four selected genes in Xinong 538 and Zhoumai 18. Expression levels of corresponding genes were normalized against expression to $18 \mathrm{~S}$ as the reference. dai $=$ days after inoculation, and $\mathrm{PR}=$ pathogenesis-related protein. 
greenhouse and field conditions (Mackintosh et al. 2007). In addition, other disease-related genes such as WRKY 33 and MPK 1-like were also induced by $F$. graminearum infection and overexpression of these genes might enhance FHB resistance (Anand et al. 2003). Thapa et al. (2018) found that upon Fusarium infection, expression of the wheat TaLRRK$6 D$ gene in cultivar CM82036 (resistant) was higher than in cultivar Remus (susceptible). Virus-induced gene silencing of the TaLRRK-6D in wheat and its homolog $H v L R R K-6 H$ in barley also enhanced FHB susceptibility, which underscores the idea that induced expression of TaLRRK-6D contributes to FHB resistance in cultivar CM82036.

Wheat deploys plant hormone pathways such as those for synthesis of ABA, SA, and JA to defend against infection by $F$. graminearum (Eldakak et al. 2018), which triggers the suicide of infected cells. The hypersensitive response is known as the major strategy deployed by the host to limit pathogen colonization. The JA and SA signaling pathways are generally activated 6 to $24 \mathrm{~h}$ after $F$. graminearum infection and trigger a cascade of resistance reactions such as the production of PR protein, cell wall

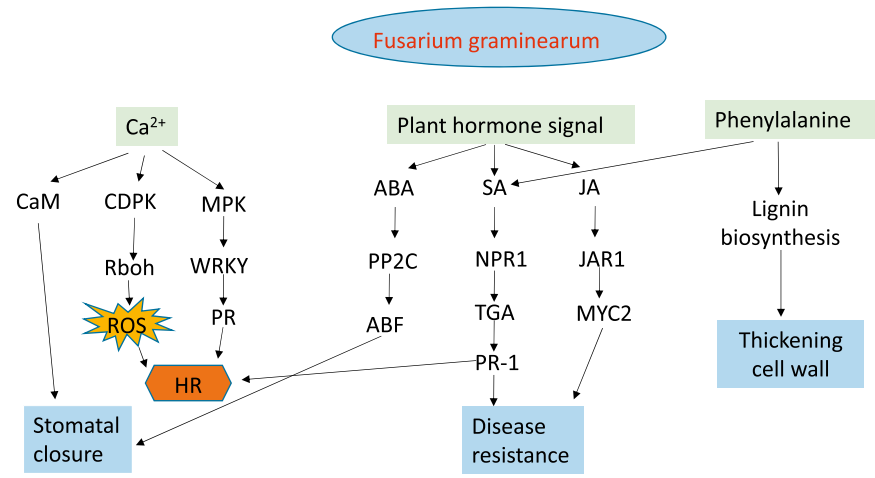

Fig. 7. Illustration of the major proteomic changes taking place after Fusarium graminearum infection in wheat. $\mathrm{CaM}=$ camalexin, $\mathrm{CDPK}=$ calcium-dependent protein kinase, $\mathrm{Rboh}=$ respiratory burst oxidase, $\mathrm{ROS}=$ reactive oxygen species, $\mathrm{HR}=$ hypersensitive response, MPK = mitogen-activated protein kinase, WRKY = WRKY transcription factor, $\mathrm{PR}=$ pathogenesis-related, $\mathrm{ABA}=$ abscisic acid, $\mathrm{PP} 2 \mathrm{C}=$ protein phosphatase $2 \mathrm{C}, \mathrm{ABF}=\mathrm{ABA}$ responsive element binding factor, $\mathrm{SA}=$ salicylic acid, NPR $=$ non-expresser of pathogenesis-related genes, $\mathrm{TGA}=$ transcription factor TGA, JA = jasmonic acid, JAR1 = jasmonic acid-amino synthetase, and $\mathrm{MYC} 2=$ transcription factor MYC2. thickening, and synthesis of antimicrobial compounds (Salzman et al. 2005). Our proteomic data support this hypothesis that wheat responds to $F$. graminearum infection via the SA and ABA signaling pathways, and we observed that activation and accumulation of defense proteins was much more apparent in Xinong 538 than in Zhoumai 18.

Many studies of the interaction between Fusarium infection and wheat were carried out in spikelets, which may limit the information provided on the molecular process of type II resistance. Liu et al. (2019) focused on the role of rachis architecture to explore this type of resistance. They performed detailed proteomic-based comparisons in the bulked rachides of FHB-resistant and susceptible wheat genotypes, and new candidates for FHB resistance (G3LEA) and susceptibility (PAP) were identified. Pathogenesis-related proteins, phenylalanine ammonia lyase, peptidyl-proline isomerase, and ATP-binding cassette transporters were also accumulated differently at the rachis node. In another study with green fluorescent protein-expressing strains of $F$. graminearum in wheat and barley, Jansen et al. (2005) demonstrated that at 2 dai, the fungus developed hyphal mats in the subcuticular space. By 3 and 4 dai, it invaded the inner layers of the pericarp, the testa, and the aleurone. Only after 6 dai did the hyphae reach the rachis. These observations suggest that by focusing on rachis nodes alone, one might miss some early host-parasite interactions. The study conducted by Pritsch et al. (2000) supports this hypothesis, as they documented the early steps in the development of $F$. graminearum in glume tissue within $76 \mathrm{~h}$ after infection and showed that hyphal penetration of glumes occurred through stomata. However, in that spray inoculation-based study, no major difference was found in the initial infection and invasion of glumes of wheat genotype Sumai 3 with a type II resistant cultivar and a susceptible wheat genotype. The intent was to determine whether floret injection can make a difference between type II resistant and susceptible wheat cultivars, specifically when the fungus is delivered to the inner glumes. After penetration, subcuticular and intercellular growth of $F$. graminearum took place during the first $48 \mathrm{~h}$ of infection (Jansen et al. 2005; Pritsch et al. 2000). Inner surfaces of the spikelet palea, lemma, and glumes are invaded more easily than the respective outer surfaces (Kang and Buchenauer 2000; Walter et al. 2010). In this study, the inner glumes were used to explore the early interaction between Fusarium infection and wheat, as we hypothesized that intensive molecular activity would take place at the early infection stage.
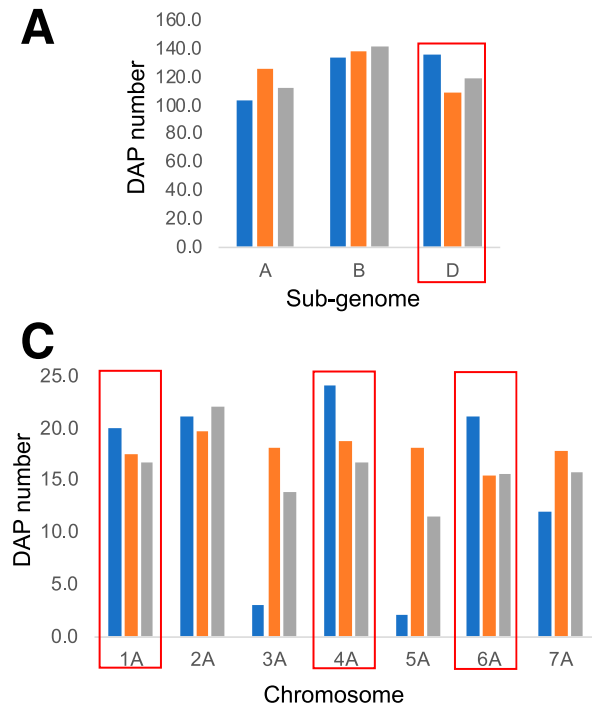

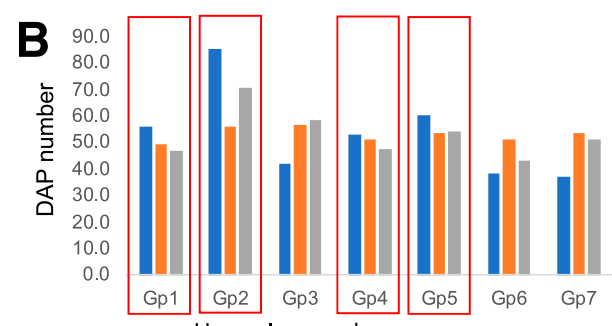

\section{D}

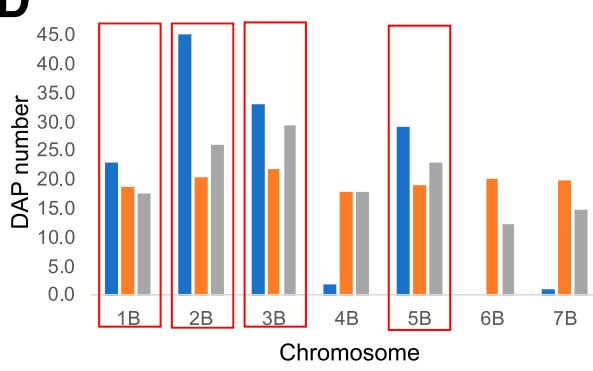

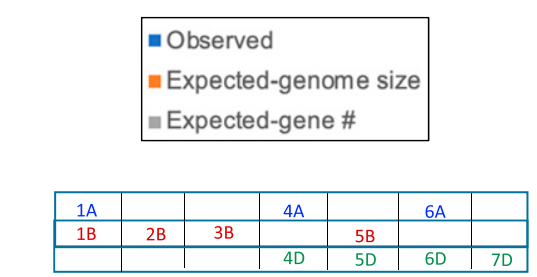

E

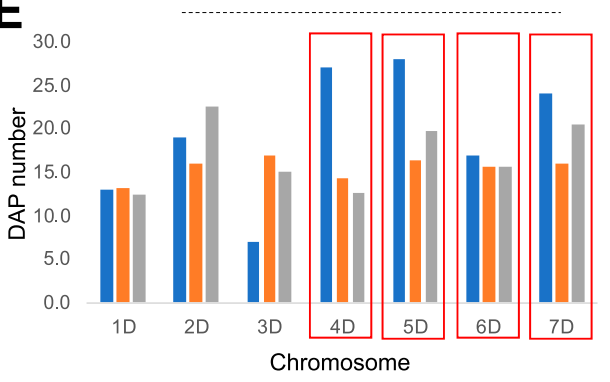

Fig. 8. Bar diagrams illustrating the distribution of differentially accumulated proteins (DAPs) on A, the subgenomes, B, homeologous chromosome groups, and C, D, and E, specific chromosomes with the observed and expected number of DAPs computed based on genome/chromosome size or gene number. Rectangular boxes are used to mark the subgenomes, homeologous chromosome groups, and specific chromosomes with more than the expected number of DAPs mapping to them. 
In this study, 371 of 391 DAPs detected in both wheat cultivars were assigned to all wheat chromosomes except chromosome 6B. The DAPs showed a biased distribution on wheat chromosomes, with more DAPs mapped to centromeric/pericentromeric regions. This distribution on the genetic map could reflect the biased recombination pattern on the chromosome axis (Erayman et al. 2004). In addition, more DAPs mapped to chromosomes $1 \mathrm{~A}, 4 \mathrm{~A}$, $6 \mathrm{~A}, 1 \mathrm{~B}, 2 \mathrm{~B}, 3 \mathrm{~B}, 5 \mathrm{~B}, 4 \mathrm{D}, 5 \mathrm{D}, 6 \mathrm{D}$, and 7D (Fig. 8C to E) than to other chromosomes irrespective of their size and gene number. Among these chromosomes, about $30 \%$ of DAPs mapped to chromosomes 2B, 3B, 5B, and 5D. Interestingly, in several earlier studies, major QTLs for FHB resistance were also identified on these chromosomes (Buerstmayr et al. 2002, 2003, 2012; Cai et al. 2019; Gervais et al. 2003; Jia et al. 2005; Li et al. 2019; Lin et al. 2004; Liu et al. 2007; Ma et al. 2006; Miedaner et al. 2006; Ollier et al. 2020; Steiner et al. 2019; Venske et al. 2019; Zhu et al. 2016). The

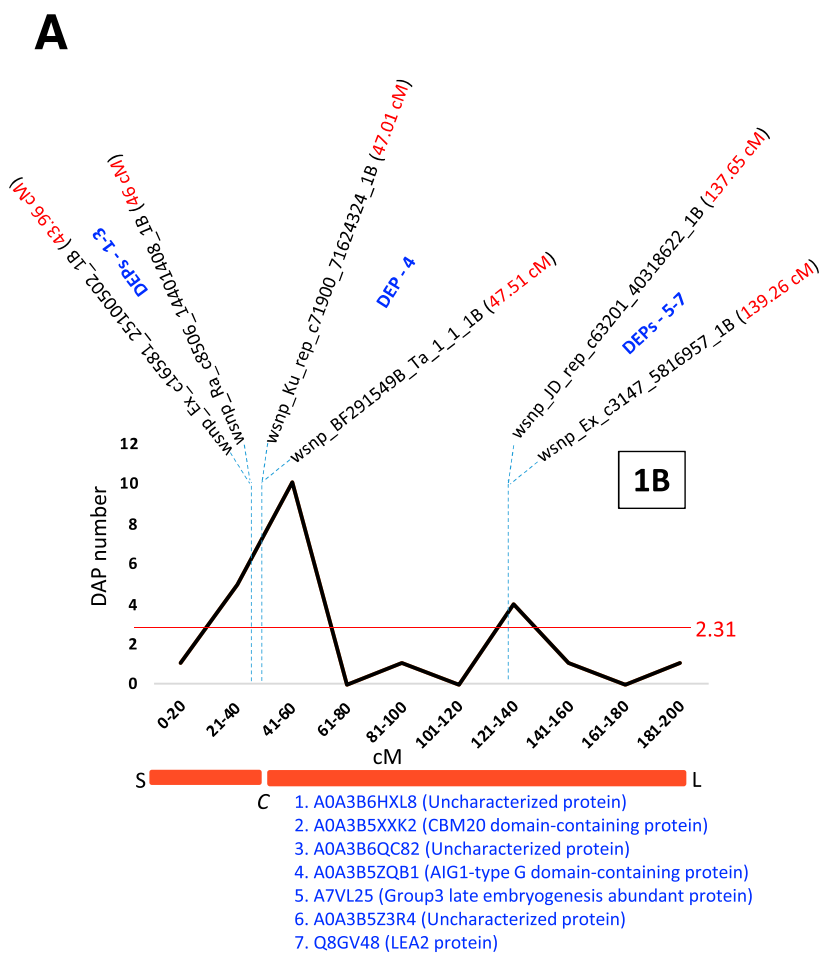

B

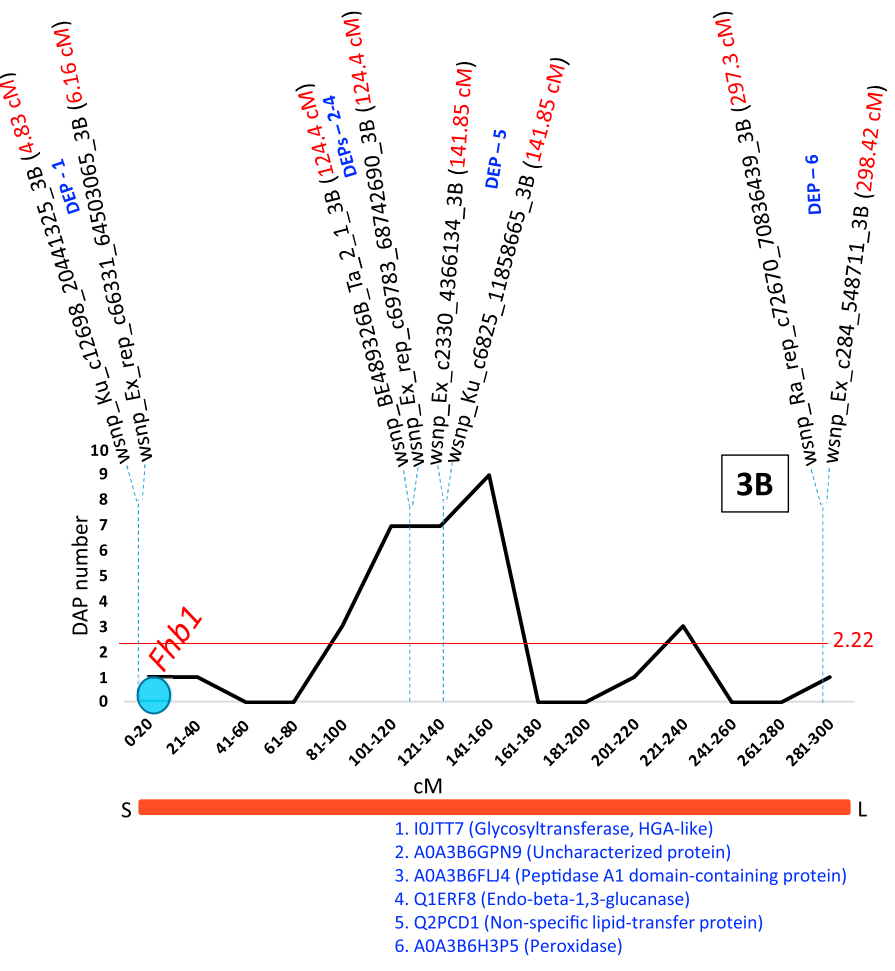

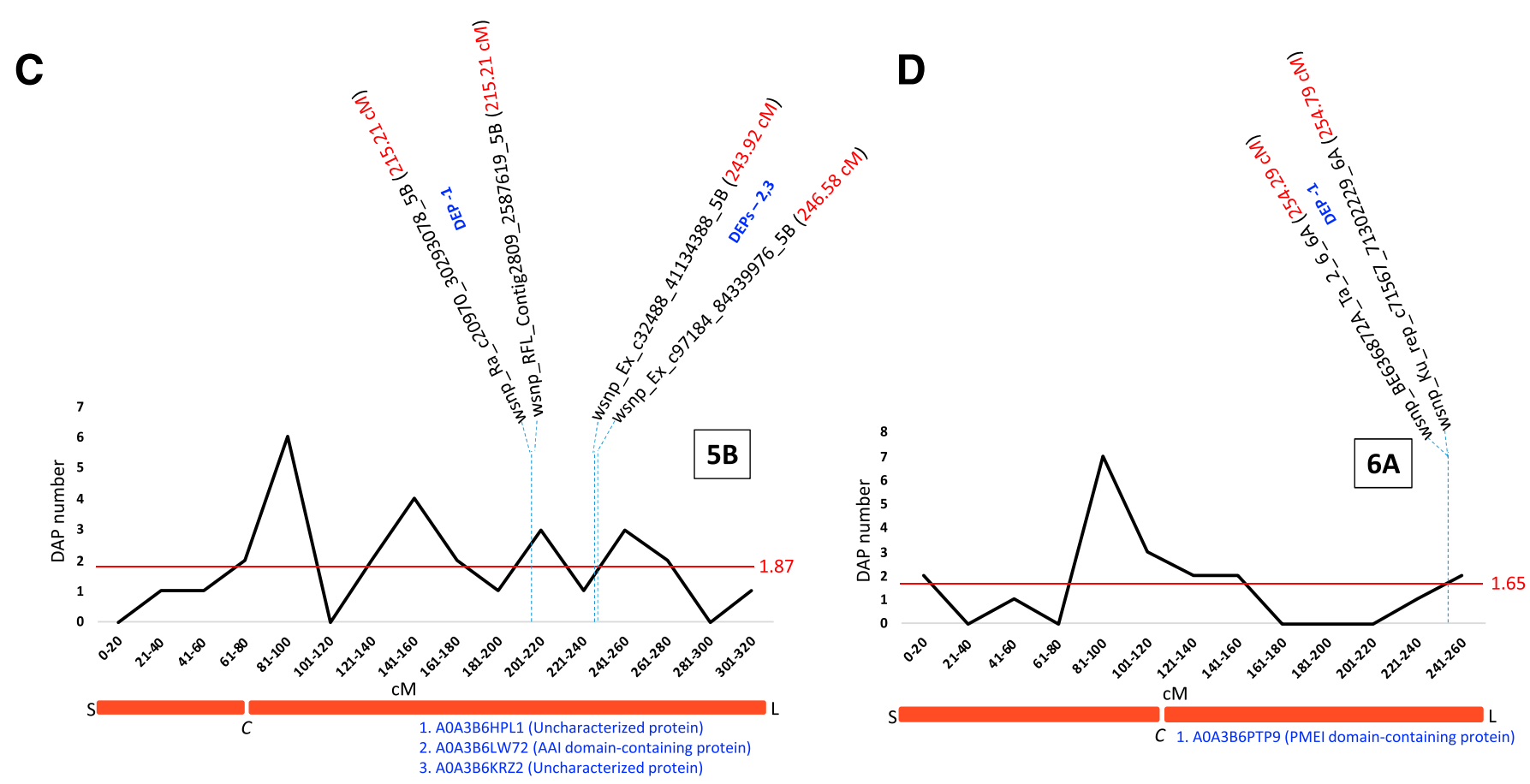

Fig. 9. Line diagrams illustrating the chromosomal distribution of differentially accumulated proteins (DAPs). Diagrams are shown for chromosomes A, 1B, B, 3B, C, 5B, and D, 6A. Centimorgan locations of genes and centromeres on each chromosome were determined based on the wheat chromosome zippers. Peaks in the chromosome plots represent the number of DAPs mapping to arbitrary chromosome bins of $20 \mathrm{cM}$ each. The expected number of DAPs mapping to each chromosome bin of $20 \mathrm{cM}$ was calculated and displayed on each plot as a horizontal line. Locations of single nucleotide polymorphism markers that flank selected DAPs which overlap with the location of earlier identified Fusarium head blight (FHB) resistance quantitative trait loci are shown on the map. The approximate location of the FHB1 locus on chromosome 3B is also shown. Molecular functions of the selected DAPs are also shown below each plot. S $=$ short arm of the chromosome, $\mathrm{L}=$ long arm of the chromosome, and $\mathrm{C}=$ centromere. 
genomic locations of 17 DAPs flanked by 20 markers that mapped to chromosomes $1 \mathrm{~B}, 3 \mathrm{~B}, 5 \mathrm{~B}$, and $6 \mathrm{~A}$ overlapped with the locations of the previously identified FHB-resistance QTLs (Laskar et al. 2017). One of the sites flanked by SNP markers $w s n p \_K u \_c 12698 \_$ $20441325 \_3 B(4.83 \mathrm{cM})$ and $w s n p \_E x \_r e p \_c 66331 \_64503065 \_3 \bar{B}$ $(6.16 \mathrm{cM})$ on chromosome 3B overlaps with the location of Fhbl (Fig. 9B) (Rawat et al. 2016). When we checked the functions of the DAPs overlapping with the FHB resistance QTLs, two DAPs mapping to chromosome $1 \mathrm{~B}$ were annotated as the late embryogenesis abundant protein and five DAPs mapping to chromosome $3 \mathrm{~B}$ as glycosyltransferase, peptidase $\mathrm{A} 1$, endo- $\beta-1,3$-glucanase, nonspecific lipid transfer protein, and peroxidase (Fig. 9). Some of these proteins were previously shown to have a role in providing resistance to fungal pathogens (Balasubramanian et al. 2012; Duplessis et al. 2011; Liu et al. 2015; Mir et al. 2015; Niu and Wang 2020; Pasquet et al. 2016). Therefore, these DAPs might serve as candidates for further functional characterization.

In summary, this study used comparative proteomic analysis to shed light on the molecular mechanisms contributing to FHB resistance in wheat cultivar Xinong 538. In this quest, iTRAQ technology provided a large amount of data on the changes in abundance of different protein species upon $F$. graminearum infection of wheat. Many metabolic pathways, especially those concerning plant-pathogen interactions, play a critical role in defense responses to $F$. graminearum in wheat. Several differentially abundant proteins, such as PR proteins, chitinase, thaumatin-like 1 , glycosyltransferase, peptidase A1, endo- $\beta$-1,3-glucanase, nonspecific lipid transfer protein, and peroxidase, could serve as candidates for further functional studies. Altogether, this work contributed to our understanding of the early stages of FHB resistance in wheat at the proteome level.

\section{LITERATURE CITED}

Anand, A., Zhou, T., Trick, H. N., Gill, B. S., Bockus, W. W., and Muthukrishnan, S. 2003. Greenhouse and field testing of transgenic wheat plants stably expressing genes for thaumatin-like protein, chitinase and glucanase against Fusarium graminearum. J. Exp. Bot. 54:1101-1111

Balasubramanian, V., Vashisht, D., Cletus, J., and Sakthivel, N. 2012. Plant $\beta$-1,3-glucanases: Their biological functions and transgenic expression against phytopathogenic fungi. Biotechnol. Lett. 34:1983-1990.

Bernardo, A., Bai, G., Guo, P., Xiao, K., Guenzi, A. C., and Ayoubi, P. 2007. Fusarium graminearum-induced changes in gene expression between Fusarium head blight-resistant and susceptible wheat cultivars. Funct. Integr. Genomics 7:69-77.

Bottalico, A., and Perrone, G. 2002. Toxigenic Fusarium species and mycotoxins associated with head blight in small-grain cereals in Europe. Eur. J. Plant Pathol. 108:611-624.

Buerstmayr, H., Lemmens, M., Hartl, L., Doldi, L., Steiner, B., Stierschneider, M., and Ruckenbauer, P. 2002. Molecular mapping of QTLs for Fusarium head blight resistance in spring wheat. I. Resistance to fungal spread (type II resistance). Theor. Appl. Genet. 104:84-91.

Buerstmayr, H., Steiner, B., Hartl, L., Griesser, M., Angerer, N., Lengauer, D., Miedaner, T., Schneider, B., and Lemmens, M. 2003. Molecular mapping of QTLs for Fusarium head blight resistance in spring wheat. II. Resistance to fungal penetration and spread. Theor. Appl. Genet. 107:503-508.

Buerstmayr, M., Huber, K., Heckmann, J., Steiner, B., Nelson, J. C., and Buerstmayr, H. 2012. Mapping of QTL for Fusarium head blight resistance and morphological and developmental traits in three backcross populations derived from Triticum dicoccum $\times$ Triticum durum. Theor. Appl. Genet. 125:1751-1765.

Cai, J., Wang, S., Su, Z., Li, T., Zhang, X., and Bai, G. 2019. Meta-analysis of QTL for Fusarium head blight resistance in Chinese wheat landraces. Crop J. 7:784-798.

Chen, W. P., Chen, P. D., Liu, D. J., Kynast, R., Friebe, B., Velazhahan, R., Muthukrishnan, S., and Gill, B. S. 1999. Development of wheat scab symptoms is delayed in transgenic wheat plants that constitutively express a rice thaumatin-like protein gene. Theor. Appl. Genet. 99:755-760.

Duplessis, S., Cuomo, C. A., Lin, Y.-C., Aerts, A., Tisserant, E., Veneault-Fourrey, C., Joly, D. L., Hacquard, S., Amselem, J., Cantarel, B. L., and Chiu, R. 2011. Obligate biotrophy features unraveled by the genomic analysis of rust fungi. Proc. Natl. Acad. Sci. U.S.A. 108:9166-9171.

Eggert, K., and Pawelzik, E. 2011. Proteome analysis of Fusarium head blight in grains of naked barley (Hordeum vulgare subsp. nudum). Proteomics 11:972-985.
Eggert, K., Zorb, C., Muhling, K. H., and Pawelzik, E. 2011. Proteome analysis of Fusarium infection in emmer grains (Triticum dicoccum). Plant Pathol. 60:918-928.

Eldakak, M., Das, A., Zhuang, Y. B., Rohila, J. S., Glover, K., and Yen, Y. 2018. A quantitative proteomics view on the function of Qfhb1, a major QTL for Fusarium head blight resistance in wheat. Pathogens 7:58.

Erayman, M., Sandhu, D., Sidhu, D., Dilbirligi, M., Baenziger, P. S., and Gill, K. S. 2004. Demarcating the gene-rich regions of the wheat genome. Nucleic Acids Res. 32:3546-3565.

Fabre, F., Vignassa, M., Urbach, S., Langin, T., and Bonhomme, L. 2019. Time-resolved dissection of the molecular crosstalk driving Fusarium head blight in wheat provides new insights into host susceptibility determinism. Plant Cell Environ. 42:2291-2308.

Gamir, J., Darwiche, R., Hof, P., Choudhary, V., Stumpe, M., Schneiter, R., and Mauch, F. 2017. The sterol-binding activity of pathogenesis-related protein 1 reveals the mode of action of an antimicrobial protein. Plant J. 89: 502-509.

Geddes, J., Eudes, F., Laroche, A., and Selinger, L. B. 2008. Differential expression of proteins in response to the interaction between the pathogen Fusarium graminearum and its host, Hordeum vulgare. Proteomics 8: 545-554.

Gervais, L., Dedryver, F., Morlais, J. Y., Bodusseau, V., Negre, S., Bilous, M., Groos, C., and Trottet, M. 2003. Mapping of quantitative trait loci for field resistance to Fusarium head blight in an European winter wheat. Theor. Appl. Genet. 106:961-970.

Hao, Y., Rasheed, A., Zhu, Z., Wulff, B. B. H., and He, Z. 2020. Harnessing wheat Fhbl for Fusarium resistance. Trends Plant Sci. 25:1-3.

Jansen, C., von Wettstein, D., Schafer, W., Kogel, K. H., Felk, A., and Maier, F. J. 2005. Infection patterns in barley and wheat spikes inoculated with wild-type and trichodiene synthase gene disrupted Fusarium graminearum. Proc. Natl. Acad. Sci. U.S.A. 102:16892-16897.

Jia, G., Chen, P., Qin, G., Bai, G., Wang, X., Wang, S., Zhou, B., Zhang, S., and Liu, D. 2005. QTLs for Fusarium head blight response in a wheat DH population of Wangshuibai/Alondra's'. Euphytica 146:183-191.

Kang, Z. S., and Buchenauer, H. 2000. Cytology and ultrastructure of the infection of wheat spikes by Fusarium culmorum. Mycol. Res. 104:1083-1093.

Kosová, K., Chrpova, J., Santrucek, J., Hynek, R., Sterbova, L., Vitamvas, P., Bradova, J., and Prasil, I. T. 2017. The effect of Fusarium culmorum infection and deoxynivalenol (DON) application on proteome response in barley cultivars Chevron and Pedant. J. Proteomics 169:112-124.

Langevin, F., Eudes, F., and Comeau, A. 2004. Effect of trichothecenes produced by Fusarium graminearum during Fusarium head blight development in six cereal species. Eur. J. Plant Pathol. 110:735-746.

Laskar, B., Luck, S., Ajay, S., and Wolters, P. 2017. Molecular markers for various traits in wheat and methods of use. U.S. Patent 9,624,553 B2

Li, G., Zhou, J., Jia, H., Gao, Z., Fan, M., Luo, Y., Zhao, P., Xue, S., Li, N., Yuan, Y., et al. 2019. Mutation of a histidine-rich calcium-binding-protein gene in wheat confers resistance to Fusarium head blight. Nat. Genet. 51: 1106-1112.

Lin, F., Kong, Z. X., Zhu, H. L., Xue, S. L., Wu, J. Z., Tian, D. G., Wei, J. B., Zhang, C. Q., et al. 2004. Mapping QTL associated with resistance to Fusarium head blight in the Nanda2419 $\times$ Wangshuibai population. I. Type II resistance. Theor. Appl. Genet. 109:1504-1511.

Liu, F., Zhang, X., Lu, C., Zeng, X., Li, Y., Fu, D., and Wu, G. 2015. Nonspecific lipid transfer proteins in plants: Presenting new advances and an integrated functional analysis. J. Exp. Bot. 66:5663-5681.

Liu, J. J., Li, L., Foroud, N. A., Gong, X., Li, C. C., and Li, T. 2019. Proteomics of bulked rachides combined with documented QTL uncovers genotype nonspecific players of the Fusarium head blight responses in wheat. Phytopathology 109:111-119.

Liu, S., Abate, Z. A., Lu, H., Musket, T., Davis, G. L., and McKendry, A. L. 2007. QTL associated with Fusarium head blight resistance in the soft red winter wheat Ernie. Theor. Appl. Genet. 115:417-427.

Liu, S. Y., Hall, M. D., Griffey, C. A., and Mckendry, A. 2009. Meta-analysis of QTL associated with Fusarium head blight resistance in wheat. Crop Sci. 49:1955-1968

Ma, H. X., Bai, G. H., Zhang, X., and Lu, W. Z. 2006. Main effects, epistasis, and environmental interactions of quantitative trait loci for Fusarium head blight resistance in a recombinant inbred population. Phytopathology 96: 534-541.

Mackintosh, C. A., Lewis, J., and Radmer, L. E. 2007. Overexpression of defense response genes in transgenic wheat enhances resistance to Fusarium head blight. Plant Cell Rep. 26:479-488.

Miedaner, T., Reinbrecht, C., Lauber, U., Schollenberger, M., and Geiger, H. H. 2001. Effects of genotype and genotype $\times$ environment interaction on deoxynivalenol accumulation and resistance to Fusarium head blight in rye, triticale, and wheat. Plant Breed. 120:97-105.

Miedaner, T., Wilde, F., Steiner, B., Buerstmayr, H., Korzun, V., and Ebmeyer, E. 2006. Stacking quantitative trait loci (QTL) for Fusarium head blight 
resistance from non-adapted sources in an European elite spring wheat background and assessing their effects on deoxynivalenol (DON) content and disease severity. Theor. Appl. Genet. 112:562-569.

Mir, A. A., Park, S. Y., Abu Sadat, M., Kim, S., Choi, J., Jeon, J., and Lee, Y. H. 2015. Systematic characterization of the peroxidase gene family provides new insights into fungal pathogenicity in Magnaporthe oryzae. Sci. Rep. 5:11831.

Niu, L., and Wang, W. 2020. Defensive forwards: Stress-responsive proteins in cell walls of crop plants. bioRxiv 950535 .

Ollier, M., Talle, V., Brisset, A. L., Le Bihan, Z., Duerr, S., Lemmens, M., Goudemand, E., Robert, O., Hilbert, J. L., and Buerstmayr, H. 2020. QTL mapping and successful introgression of the spring wheat-derived QTL Fhb1 for Fusarium head blight resistance in three European triticale populations. Theor. Appl. Genet. 133:457-477.

Pasquet, J. C., Changenet, V., Macadré, C., Boex-Fontvieille, E., Soulhat, C., Bouchabké-Coussa, O., Dalmais, M., Atanasova-Pénichon, V., Bendahmane, A., Saindrenan, P., and Dufresne, M. 2016. A Brachypodium UDP-glycosyltransferase confers root tolerance to deoxynivalenol and resistance to Fusarium infection. Plant Physiol. 172:559-574.

Perlikowski, D., Wisniewska, H., Goral, T., Kwiatek, M., Majka, M., and Kosmala, A. 2014. Identification of kernel proteins associated with the resistance to Fusarium head blight in winter wheat (Triticum aestivum L.,). PLoS One 9:e110822.

Pritsch, C., Muehlbauer, G. J., Bushnell, W. R., Somers, D. A., and Vance, C. P. 2000. Fungal development and induction of defense response genes during early infection of wheat spikes by Fusarium graminearum.Mol. Plant-Microbe Interact. 13:159-169.

Rawat, N., Pumphrey, M. O., Liu, S., Zhang, X., Tiwari, V. K., Ando, K., Trick, H. N., Bockus, W. W., Akhunov, E., Anderson, J. A., and Gill, B. S. 2016. Wheat Fhb1 encodes a chimeric lectin with agglutinin domains and a pore-forming toxin-like domain conferring resistance to Fusarium head blight. Nat. Genet. 48:1576-1580.

Salzman, R. A., Brady, J. A., Finlayson, S. A., Buchanan, C. D., Summer, E. J., Sun, F., Klein, P. E., Klein, R. R., Pratt, L. H., Cordonnier-Pratt, M. M., and Mullet, J. E. 2005. Transcriptional profiling of sorghum induced by methyl jasmonate, salicylic acid, and aminocyclopropane carboxylic acid reveals cooperative regulation and novel gene responses. Plant Physiol. 138:352-368.

Schroeder, H. W., and Christensen, J. J. 1963. Factors affecting resistance of wheat to scab caused by Gibberella zeae. Phytopathology 53:831-838.

Shin, K. H., Kamal, A. H. M., Cho, K., Choi, J. S., Jin, Y., Paek, N. C., Lee, Y., Lee, J., Park, J., Kim, H., and Woo, S. 2011. Defense proteins are induced in wheat spikes exposed to Fusarium graminearum. Plant Omics 4:270-277.

Steiner, B., Michel, S., Maccaferri, M., Lemmens, M., Tuberosa, R., and Buerstmayr, H. 2019. Exploring and exploiting the genetic variation of Fusarium head blight resistance for genomic-assisted breeding in the elite durum wheat gene pool. Theor. Appl. Genet. 132:969-988.

Stokstad, E. 2020. Help for a wheat fungal disease comes from a surprising source. Science 368:122.

Su, Z., Bernardo, A., Tian, B., Chen, H., Wang, S., Ma, H., Cai, S., Liu, D., Zhang, D., Li, T., Trick, H., St. Amand, P., Yu, J., Zhang, Z., and Bai, G. 2019. A deletion mutation in TaHRC confers Fhbl resistance to Fusarium head blight in wheat. Nat. Genet. 51:1099-1105.
Thapa, G., Gunupuru, L. R., Heir, J. G., Kahla, A., Mullins, E., and Doohan, F. M. 2018. A pathogen-responsive leucine rich receptor like kinase contributes to Fusarium resistance in cereals. Front. Plant Sci. 9:867.

Trümper, C., Paffenholz, K., Smit, I., Kössler, P., Karlovsky, P., Braun, H. P., and Pawelzik, E. 2015. Identification of differently regulated proteins after Fusarium graminearum infection of Emmer (Triticum dicoccum) at several grain ripening stages. Food Technol. Biotechnol. 53:261-268.

Venske, E., dos Santos, R. S., Farias, D. D. R., Rother, V., Maia, L. C. D., Pegoraro, C., and Costa de Oliveira, A. 2019. Meta-analysis of the QTLome of Fusarium head blight resistance in bread wheat: Refining the current puzzle. Front. Plant Sci. 10:727.

Walter, S., Nicholson, P., and Doohan, M. 2010. Action and reaction of host and pathogen during Fusarium head blight disease. New Phytol. 185:54-66.

Wang, B., Li, X. F., Chen, W. Y., and Kong, L. R. 2019. Isobaric tags for relative and absolute quantification-based proteomic analysis of defense responses triggered by the fungal pathogen Fusarium graminearum in wheat. J. Proteomics 207:103442.

Wang, H., Sun, S., Ge, W., Zhao, L., Hou, B., Wang, K., Lyu, Z., Chen, L., Xu, S., Guo, J., and Li, M. 2020. Horizontal gene transfer of Fhb7 from fungus underlies Fusarium head blight resistance in wheat. Science 368:eaba5435.

Wang, L. N., Yin, G. H., Han, Y. L., Huang, F., Tang, J. W., Yu, H. F., Yang, G. Y., and Li, X. P. 2012. Density on yield and yield components of winter wheat Zhoumai 18. Crop J. 001:102-104.

Wang, Y., Yang, L. M., Xu, H. B., Li, Q. F., Ma, Z. Q., and Chu, C. G. 2005. Differential proteomic analysis of proteins in wheat spikes induced by Fusarium graminearum. Proteomics 5:4496-4503.

Yang, F., Jacobsen, S., Jørgensen, H. J. L., Collinge, D. B., Svensson, B., and Finnie, C. 2013. Fusarium graminearum and its interactions with cereal heads: Studies in the proteomics era. Front. Plant Sci. 4:1-8.

Yang, F., Jensen, J. D., Spliid, N. H., Svensson, B., Jacobsen, S., Jorgensen, L. N., Jorgensen, H. J. L., Collinge, D. B., and Finnie, C. 2010a. Investigation of the effect of nitrogen on severity of Fusarium head blight in barley. J. Proteomics 73:743-752.

Yang, F., Jensen, J. D., Svensson, B., Jorgensen, H. J., Collinge, D. B., and Finnie, C. 2010b. Analysis of early events in the interaction between Fusarium graminearum and the susceptible barley (Hordeum vulgare) cultivar Scarlett. Proteomics 10:3748-3755.

Yang, M. M., Gao, X., Dong, J., Gandhi, N., Cai, H., von Wettstein, D., Rustgi, S., and Wen, S. S. 2017. Pattern of protein expression in developing wheat grains identified through proteomic analysis. Front. Plant Sci. 8:1-13.

Yang, M. M., Liu, Y., Dong, J., Zhao, W. C., Kashyap, S., Gao, X., Rustgi, S., and Wen, S. S. 2020. Probing early wheat grain development via transcriptomic and proteomic approaches. Funct. Integr. Genomics 20:63-74.

Zhou, W., Eudes, F., and Laroche, A. 2006. Identification of differentially regulated proteins in response to a compatible interaction between the pathogen Fusarium graminearum and its host, Triticum aestivum. Proteomics 6:4599-4609.

Zhu, Z., Bonnett, D., Ellis, M., He, X., Heslot, N., Dreisigacker, S., Gao, C., and Singh, P. 2016. Characterization of Fusarium head blight resistance in a CIMMYT synthetic-derived bread wheat line. Euphytica 208:367-375. 